\title{
Therapeutic Effect of a Novel Chimeric Molecule Targeting Both Somatostatin and Dopamine Receptors on Growth Hormone-Secreting Pituitary Adenomas
}

\author{
Jean Kim ${ }^{1,2,}$, Ju Hun $\mathrm{Oh}^{1,2, *}$, Heather Harlem³ ${ }^{3}$ Michael D. Culler ${ }^{3}$, Cheol Ryong Ku², Eun Jig Lee \\ ${ }^{1}$ Brain Korea 21 PLUS Project for Medical Science, Yonsei University; ${ }^{2}$ Endocrinology, Institute of Endocrine Research, Yonsei \\ University College of Medicine, Seoul, Korea; ${ }^{3}$ Endocrinology Research, Ipsen Bioscience Inc., Cambridge, MA, USA
}

Background: Acromegaly is a rare disease primarily caused by growth hormone $(\mathrm{GH})$-secreting pituitary adenomas, and its treatment is costly. Moreover, some patients are unresponsive to treatment. Hence, there are increasing efforts to develop new drugs with improved effectiveness for this disease. BIM23B065 is a novel chimeric molecule that acts on both somatostatin and dopamine receptors. This study aimed to investigate the effects of BIM23B065 compared with those of a somatostatin receptor analog and a dopamine agonist.

Methods: The effects of BIM23B065 on the proliferation, GH and insulin-like growth factor-1 (IGF-1) levels, and extracellular signal-regulated kinase (ERK) 1/2 and cyclic AMP response element binding (CREB) phosphorylation of GH3 cells were investigated with MTS assay, enzyme-linked immunosorbent assay, and Western blotting, respectively. The dosage and treatment duration of BIM23B065 were tested in animal models of GH-secreting pituitary adenoma. The effect of BIM23B065 (3 mg/ $\mathrm{kg} /$ day) on changes in IGF-1 levels before and after treatment was further investigated.

Results: In vitro, BIM23B065 treatment decreased GH release in the culture media and downregulated ERK 1/2 and CREB phosphorylation to $22 \%$ and $26 \%$, respectively. In vivo, IGF-1 expression decreased to $50 \%$ after 4 weeks of treatment with BIM23B065 using an osmotic pump implant. Moreover, magnetic resonance imaging results showed that the tumor size decreased significantly following treatment with BIM23B065 for 4 weeks.

Conclusion: The novel chimeric molecule was effective in decreasing IGF-1 and GH levels and may serve as an effective therapeutic agent for acromegaly.

Keywords: Acromegaly; Therapeutics; Growth hormone; Insulin-like growth factor I; Pituitary neoplasms

Received: 6 November 2019, Revised: 12 January 2020,

Accepted: 28 January 2020

Corresponding authors: Eun Jig Lee

Endocrinology, Institute of Endocrine Research, Yonsei University College of

Medicine, 50-1 Yonsei-ro, Seodaemun-gu, Seoul 03722, Korea

Tel: +82-2-2228-0833, Fax: +82-2-393-6884, E-mail: ejlee423@yuhs.ac

Cheol Ryong $\mathrm{Ku}$

Endocrinology, Institute of Endocrine Research, Yonsei University College of

Medicine, 50-1 Yonsei-ro, Seodaemun-gu, Seoul 03722, Korea

Tel: +82-2-2228-0872, Fax: +82-2-393-6884, E-mail: cr079@yuhs.ac

\section{Copyright $@ 2020$ Korean Endocrine Society}

This is an Open Access article distributed under the terms of the Creative Commons Attribution Non-Commercial License (https://creativecommons.org/ licenses/by-nc/4.0/) which permits unrestricted non-commercial use, distribution, and reproduction in any medium, provided the original work is properly cited.

*These authors contributed equally to this work. 


\section{INTRODUCTION}

Acromegaly is a disease characterized by chronic growth hormone (GH) and insulin-like growth factor-1 (IGF-1) hypersecretion $[1,2]$. It is primarily caused by a GH-secreting pituitary adenoma. Although surgical resection of the pituitary adenoma is the first choice of treatment for many patients, it restores normal IGF-1 levels in less than $60 \%$ of cases [1,2]. In patients unsuitable or unwilling to undergo surgery, or in whom surgery fails to normalize plasma GH and IGF-1 concentrations, pharmacological intervention is the standard procedure $[1,2]$.

Somatostatin (SST) analogs and dopamine agonists (DAs) are useful in treating GH-secreting pituitary adenoma [3-5]. As GHsecreting pituitary adenomas are associated with increased expression of SST and dopamine receptors, drugs targeting these receptors hold therapeutic potential against acromegaly [3-7]. However, they are relatively less effective for controlling hormonal secretion and reducing tumor sizes [2-8]. SST analogs, such as lanreotide, have been consistently shown to reduce hormonal hypersecretion in $60 \%$ to $70 \%$ of patients [1-3], whereas DAs, such as cabergoline (CAB), may be effective in up to $30 \%$ of patients with mildly elevated plasma IGF-1 concentrations $[1,2]$. SST and DAs are useful for the treatment of acromegaly, but they are not cost-effective and cases of unresponsiveness as well as resistance have been reported [9]. Therefore, there is a need for alternative pharmacological approaches to treat acromegaly.

Recently, a series of novel chimeric molecules consisting of a SST analog and a DA have been synthesized and are currently being tested [10-14]. The chimeric molecule used in this study acts on both SST receptors 2 and 5 as well as on dopamine receptor subtype 2; thus, it can be a promising candidate for the treatment of acromegaly and GH-secreting pituitary adenoma.

The main purpose of this study was to confirm the effect of BIM23B065 on GH-secreting pituitary adenoma and provide evidence for its approval as a new therapeutic option for acromegaly. Owing to increased efficiency via differentiated mechanisms, this chimeric drug is expected to overcome the low rate of responsiveness to previously used drugs.

\section{METHODS}

\section{Ethical statement}

The Institutional Animal Care and Use Committee of Yonsei University Health System reviewed and approved (approval number: 2015-0403) all animal procedures. Experiments were carried out under the strict guidance of the Association for Assessment and Accreditation of Laboratory Animal Care. Animals were housed under standard conditions consisting of 12hour light/dark cycles (lights were turned on at 7:00 AM) and a temperature of $22^{\circ} \mathrm{C}$ to $24^{\circ} \mathrm{C}$. The animals had ad libitum access to standard rodent chow and water, except during intended fasting periods designated for specific experimental protocols. All mice were maintained in accordance with the American Association of Laboratory Animal Care guidelines.

\section{Cell culture}

For in vitro experiments, the rat pituitary tumor cell line GH3 (American Type Culture Collection) was used. These cells were grown in Dulbecco's modified Eagle medium (DMEM)/highglucose medium supplemented with $10 \%$ fetal bovine serum and penicillin-streptomycin solution (Hyclone Co., Logan, UT, USA). The cells were placed in a culture incubator that maintained atmospheric conditions of $37^{\circ} \mathrm{C}$ and $5 \% \mathrm{CO}_{2}$. The medium was changed within 3 days, and the cells were split with trypsin/ethylenediaminetetraacetic acid (EDTA) every week.

\section{Experimental animals}

The animal model used in this study was a previously developed mouse model, which expressed the phenotype of GH-secreting pituitary adenomas [8]. A somatotroph-specific aryl hydrocarbon receptor interacting protein knockout (sAIPKO) mouse model was established using rGHp-Cretg/+; Aiplox/lox mice [15]. All mice in this study were males above 40 weeks of age because most sAIPKO mice develop GH-secreting pituitary adenomas as they age ( $>40$ weeks).

\section{Cell proliferation assay}

To test the cytotoxicity of drugs, MTS assays were performed. GH3 cells $(100 \mu \mathrm{L})$ were seeded in a 96-well plate at a density of $4 \times 10^{3}$ cells $/$ well. After 24 hours of incubation at $37^{\circ} \mathrm{C}$ in a $5 \%$ $\mathrm{CO}_{2}$ incubator, the growth medium was replaced with DMEM/ high-glucose medium without serum to induce starvation conditions. After 12 hours, media containing three different drugs, namely lanreotide $(5,10,50,100$, or $250 \mu \mathrm{M}), \mathrm{CAB}(3,5,7,10$, or $15 \mu \mathrm{M})$, and $\mathrm{BIM} 23 \mathrm{~B} 065(5,10,50,100$, or $250 \mu \mathrm{M})$ were prepared. The control group was treated with dimethyl sulfoxide (DMSO). After treatment with drugs, the cells were incubated for 24, 48, and 72 hours in the incubator.

MTS solution (Promega, Madison, WI, USA) was diluted by mixing $150 \mu \mathrm{L}$ of the solution with $1 \mathrm{~mL}$ of medium. The cells were treated with MTS medium for 1.5 hours in the incubator. 
The optical density was observed under $495 \mathrm{~nm}$ using a spectrophotometer (Versa Max microplate reader, Molecular Devices, San Jose, CA, USA).

\section{GH and IGF-1 ELISA}

The medium collected from the cell culture was tested for changes in $\mathrm{GH}$ levels before and after drug treatment. To determine the effect of the drug in normalizing GH and IGF-1 levels in the animal model, blood serum samples collected before and after treatment were tested. GH and IGF-1 levels were measured using rat/mouse growth hormone enzyme-linked immunosorbent assay (ELISA) kit 96-Well Plates (Millipore, Billerica, MA, USA) and mouse IGF-1 ELISA kit (Abcam, Cambridge, UK), respectively, according to the manufacturer's instructions.

\section{Western blotting}

Before drug treatment, the cells were seeded and stabilized for 24 hours. After treatment with drugs for 15 minutes, the plates were washed twice with 1X Dulbecco's Phosphate-Buffered Saline. The plates were then kept on ice and treated with protein lysis buffer, which is composed of $10 \%$ glycerol, $50 \mathrm{mM} \mathrm{Na-}$ 3VO4, $100 \mathrm{mM} \mathrm{NaF,} 100 \mathrm{mM}$ phenylmethylsulfonyl fluoride, and $100 \mathrm{mM}$ dithiothreitol mixed in radioimmunoprecipitation assay (RIPA) buffer. The cells were collected in $1.5 \mathrm{~mL}$ microcentrifuge tubes using a cell scraper and incubated on ice for 1 hour with frequent mixing. The samples were then centrifuged for 20 minutes at 15,380 g, and the supernatant was transferred to new Eppendorf tubes.

The protein concentrations were measured using Bradford assay (Bio-Rad laboratories, Hercules, CA, USA) and set to 50 $\mu \mathrm{M}$ for all samples. The samples were prepared with $10 \%$ sodium dodecyl sulfate-polyacrylamide gel electrophoresis (SDSPAGE) buffer and denatured in a heating block at $95^{\circ} \mathrm{C}$ for 5 minutes.

Proteins were separated by size using gel electrophoresis and transferred to Immobilon polyvinylidene difluoride membranes by wet transfer technique. The obtained membranes were blocked with 5\% skim milk for 1 hour to prevent non-specific binding with antibodies and probed with anti-phospho-cyclic AMP response element binding (CREB) $(1: 1,000$, Cell Signaling Technology, Danvers, MA, USA), anti-total-CREB (1:1,000, Cell Signaling Technology), anti-phospho-extracellular signal-regulated kinase (ERK) 1/2 (1:2,000, Cell Signaling Technology), anti-total ERK 1/2 (1:4,000, Cell Signaling Technology) overnight at $4^{\circ} \mathrm{C}$. The membrane was washed in $1 \mathrm{X}$
TBS-T solution and reacted with the secondary antibody (1:4,000, Thermo Fisher Scientific, Waltham, MA, USA) for another 1 hour at room temperature. After TBS-T washing, proteins on the membrane were detected using a West Save Up Western Blot detection kit (AbFrontier \#LF-QC0101) on an enhanced chemiluminescence film.

\section{Osmotic pump implantation}

Establishment of the knockout model was confirmed by genotyping. To determine the dosage of the new chimeric molecule drug, three different doses of the drug were tested on sAIPKO mice. In total, 16 male mice ( $>40$ weeks of age) were divided into four groups (vehicle, lanreotide, $\mathrm{CAB}$, and chimeric molecule groups) of four mice each.

The drug was administered for 7 days using Alzet mini-osmotic pumps (Durect Co., Cupertino, CA, USA). Osmotic pump was prepared according to the manufacturer's protocol. The drug concentration was calculated individually based on animal weight. For implantation surgery, the animals were subjected to anesthesia using isoflurane. After blood was withdrawn by retroorbital bleeding, the pump was implanted under the epidermis on the dorsal posterior side of the animals as the incision wound was clipped. Blood glucose level and body weight were measured daily to monitor the condition of the animals.

After the concentration was set, the four groups were treated for one month. To reduce the stress associated with the insertion of the drug-release pumps, a 14-day release pump was used instead of a 7-day release pump. The test concentration of lanreotide was set at the same molar concentration as BIM23B065. $\mathrm{CAB}$ concentration was set based on previous animal studies $[16,17]$. The procedure and protocols were the same as the previous experiment, save for the pump type and monitoring frequency. The pump type was changed to 14-day release pump so that the pump was changed to a newly prepped pump after 2 weeks. In addition, the condition of animals was monitored every other day.

Lanreotide and BIM23B065 were provided by Ipsen (Boston, MA, USA) and CAB was purchased from Dongkoo Bio \& Pharma (Seoul, Korea).

\section{Magnetic resonance imaging}

All magnetic resonance imaging (MRI) experiments were performed on a 9.4T Bruker BioSpec 94/20 USR small animal imaging system (Bruker BioSpin MRI GmbH, Ettlingen, Germany) equipped with $1 \mathrm{H}$ mouse body coil. T2-weighted MRI scan was performed, and tumor size was measured using OsiriX DI- 
COM viewer before and after treatment with the chimeric molecule. The tumor volume was estimated according to equation 1: tumor volume $=\left(\right.$ length $\times$ width $\left.^{2}\right) / 2$ [18].

\section{Statistical analyses}

Statistical analysis was performed using Microsoft Excel (Microsoft, Redmond, WA, USA). The results are expressed as mean \pm standard error of the mean of the results from three independent experiments with similar patterns. Differences were assessed by analysis of variance (ANOVA). $P<0.05$ was considered significant

\section{RESULTS}

\section{Proliferation assay}

The half maximal inhibitory concentration (IC50) in GH3 cells was measured to determine the effect of the chimeric molecule as well as that of the positive controls ( $\mathrm{CAB}$ and lanreotide). After 72 hours of treatment with $250 \mu \mathrm{M}$ BIM23B065, the cell viability decreased to $43 \%$. Cell viability decreased to $53 \%$ and $49 \%$ after 72 hours of treatment with $250 \mu \mathrm{M}$ lanreotide and 15 $\mu \mathrm{M}$ CAB, respectively (Fig. 1A).

\section{Changes in CREB and ERK 1/2 phosphorylation}

After the proliferation assay, each drug was tested at the IC80 concentration to evaluate their effects on GH3 cells by checking CREB and ERK 1/2 phosphorylation. After 15 minutes of treatment, BIM23B065 decreased CREB phosphorylation by approximately $26 \%$, while lanreotide and the combination of CAB and lanreotide decreased CREB phosphorylation by only $16 \%$ and $18 \%$, respectively. CAB decreased CREB phosphorylation by $9 \%$. BIM23B065 and lanreotide downregulated p-ERK 1/2 level by $22 \%$ compared to the control. However, $\mathrm{CAB}$ and the combination of lanreotide and $\mathrm{CAB}$ did not decrease $\mathrm{p}$-ERK level (Fig. 1C).

\section{GH level in the cell medium}

Based on the results of the cell proliferation assay, the cell medium at 48 hours was used to determine the change in GH levels. Compared with the control, all drugs decreased GH level in the medium. The GH level decreased by 3\% with lanreotide treatment, while CAB showed the greatest decrement of approximately $13 \%$. The combination of $\mathrm{CAB}$ and lanreotide exhibited a decrement of approximately $12 \%$, which is similar to the result of $\mathrm{CAB}$, and BIM23B065 decreased the level of $\mathrm{GH}$ in the medium by approximately 10\% (Fig. 1B).

\section{Dose-dependent reduction of IGF-1 by BIM23B065 in SAIPKO mice}

sAIPKO mice aged 40 weeks or above were used because pituitary adenoma incidences are reported at this age [8]. Considering that sex hormones affect the onset and aggressiveness of pituitary adenoma [8], female mice were excluded from the experiment, and the effect of estrogen was avoided.

Being a novel molecule, a dose-ranging study of BIM23B065 was conducted in this animal model at doses of 3, 4, 5, and $6 \mathrm{mg} /$ $\mathrm{kg}$ /day. After 7 days of drug treatment, most animals showed dose-dependent decreases in IGF-1 levels. IGF-1 level decreased by $37 \%$ at the dose of $3 \mathrm{mg} / \mathrm{kg} /$ day and by $47 \%$ at doses of 4,5 , and $6 \mathrm{mg} / \mathrm{kg} /$ day (Fig. 2A).

Body weight (Fig. 2B) and blood glucose level (Fig. 2C) remained constant during the treatment, with no significant changes observed before or after the treatment (Fig. 2B, C).

\section{Long-term effects of BIM23B065, lanreotide, and cabergoline}

Based on the dosage decision experiment, $3 \mathrm{mg} / \mathrm{kg} /$ day was found to be an effective concentration and used for the BIM23B065 treatment group. The mice were treated for 4 weeks with vehicle, BIM23B065, lanreotide, or CAB. Lanreotide was used at the same molar concentration as BIM23B065; therefore, its dosage was set to $2.257 \mathrm{mg} / \mathrm{kg} /$ day. $\mathrm{CAB}$ concentration was set to 0.82 $\mathrm{mg} / \mathrm{kg} /$ day based on previous reports.

After the treatment duration, IGF-1 levels decreased by $10 \%$ in the vehicle control group compared to the pre-treatment level, and by $18 \%, 50 \%$, and $49 \%$ in the CAB lanreotide, and BIM23B065 groups, respectively (Fig. 3A). No changes in body weight and blood glucose levels were observed throughout the experiment (Fig. 3B, C).

\section{MRI analysis of tumor size before and after drug treatment}

To determine the effect of BIM23B065 on tumor size, MRI was performed before and after 4-week treatment in five sAIPKO mice. Three of the five animals contained pituitary tumors and all five animals showed hyperplasia. Comparison of MRI results before and after treatment showed that the tumor size decreased by 50\% after BIM23B065 treatment (Fig. 4A). The size of the pituitary hyperplasia also decreased in all five animals; however, it decreased by $59 \%$ in two mice with tumors (Fig. 4B). Preand post-treatment MRI results are presented in Fig. 4C. 
Lanreotide
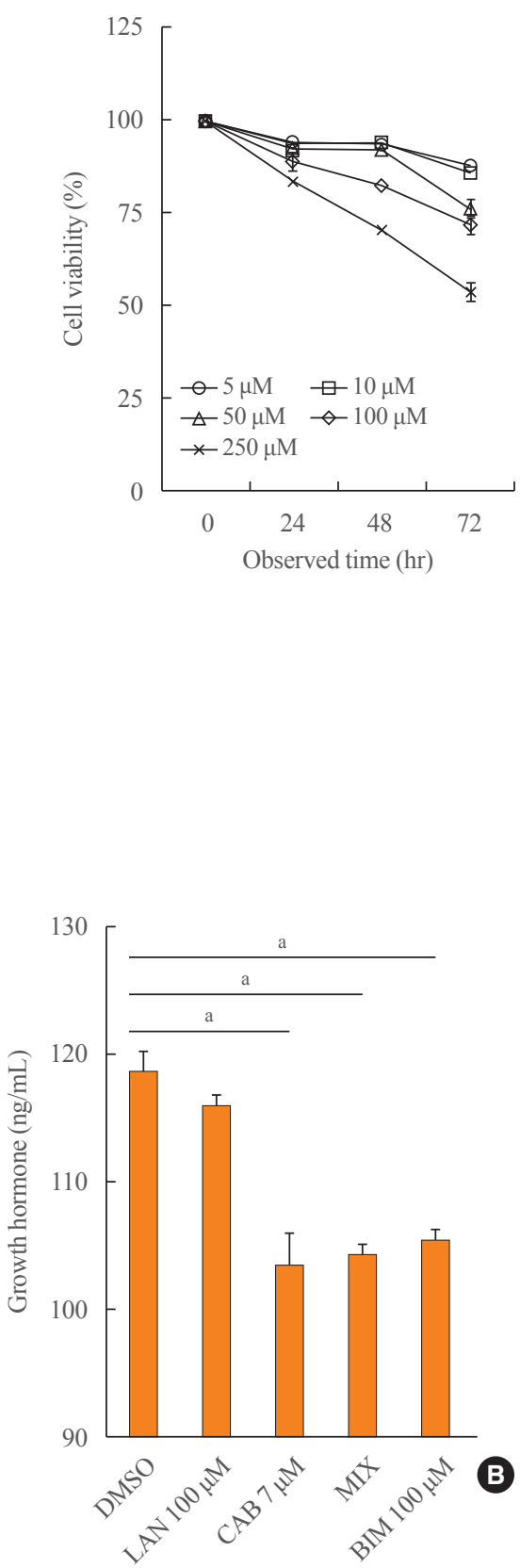

Cabergoline

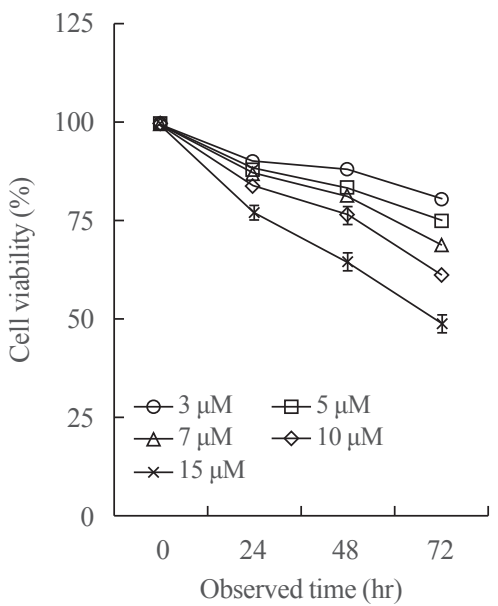

BIM23B065

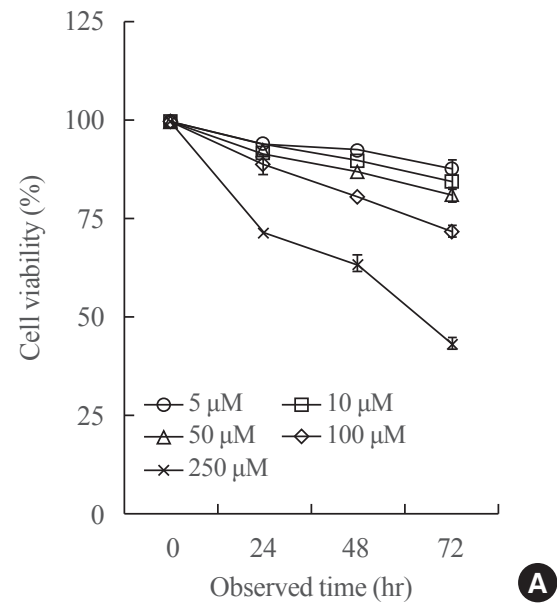

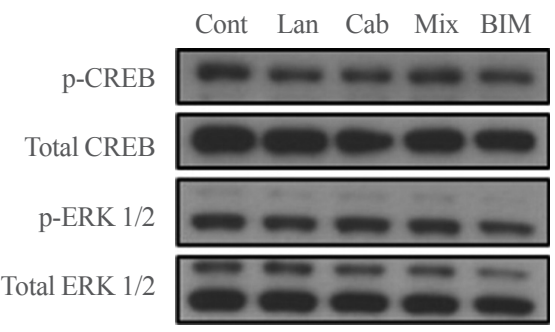
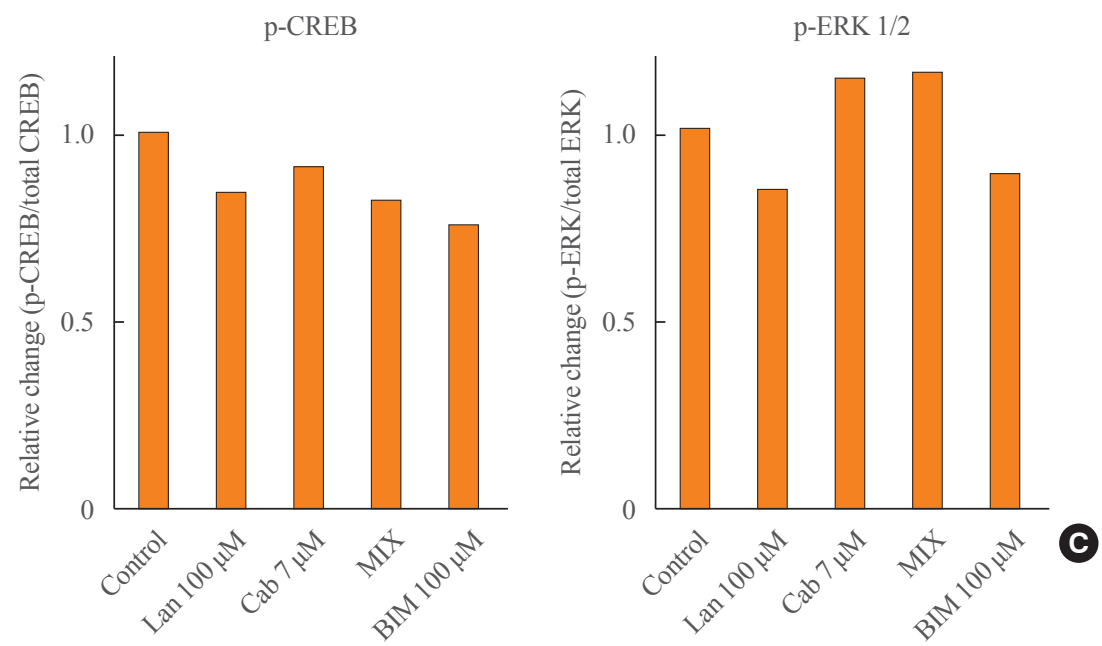

Fig. 1. Effects of lanreotide, cabergoline, and BIM23B065 on growth hormone 3 (GH3) cells. (A) Cell proliferation assay. (B) Change in growth hormone release in the medium after 48 hours of treatment. (C) Changes in phospho-cyclic AMP response element binding (pCREB) and phospho-extracellular signal-regulated kinase (p-ERK) 1/2 after 15 minutes of drug treatment. DMSO, dimethyl sulfoxide; LAN, lanreotide; CAB, cabergoline. ${ }^{a} P<0.05$.

\section{DISCUSSION}

Recently, the Acromegaly Guidelines reported that pharmaceutical treatment as well as surgical interventions can be administered as primary treatment options for acromegaly [1]. The drugs used for GH-secreting pituitary adenoma treatment act on both SST and dopamine receptors [1,2]. Although SST analogs and DAs have been reported for the treatment of GH-secreting pituitary adenomas, the response rate of SST is only between $60 \%$ to $70 \%$. Moreover, DAs are reported to be effective only in cases of mild hormonal activity [1]. Resistance to SST analogs has reduced the available treatment options. Therefore, a novel 

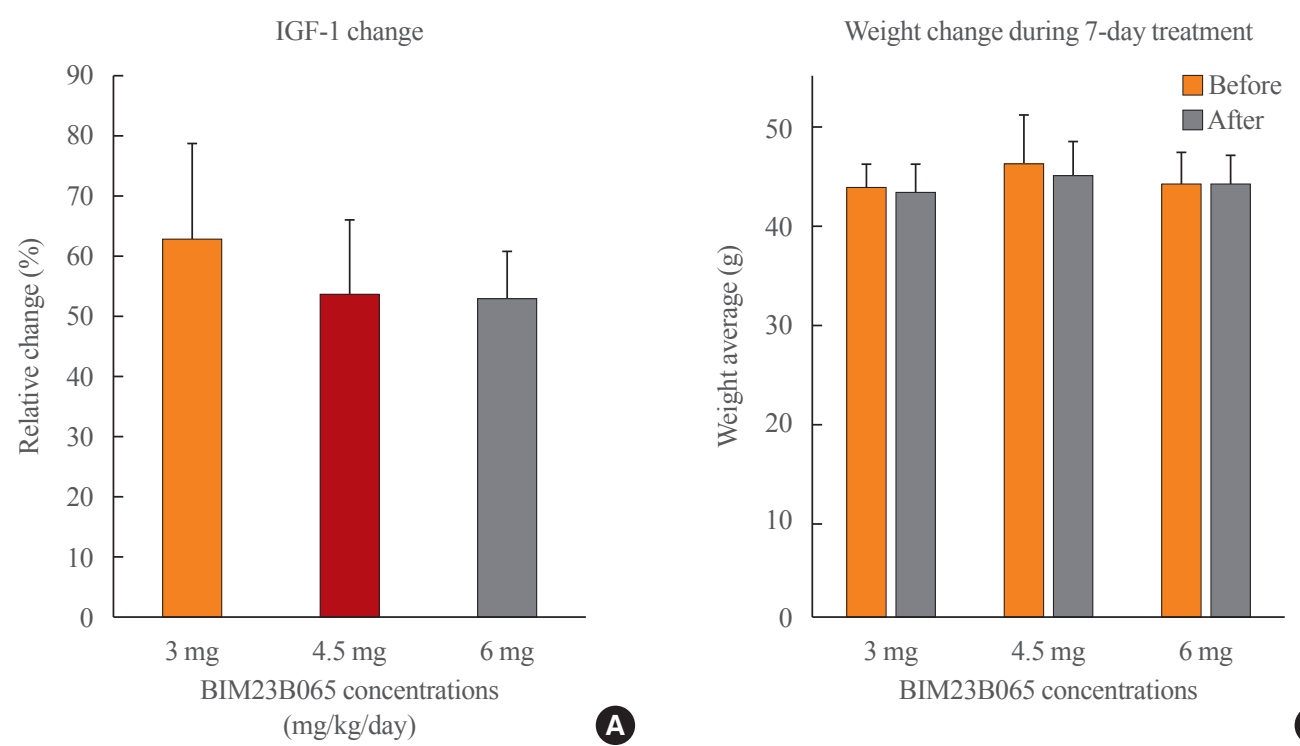

A

B

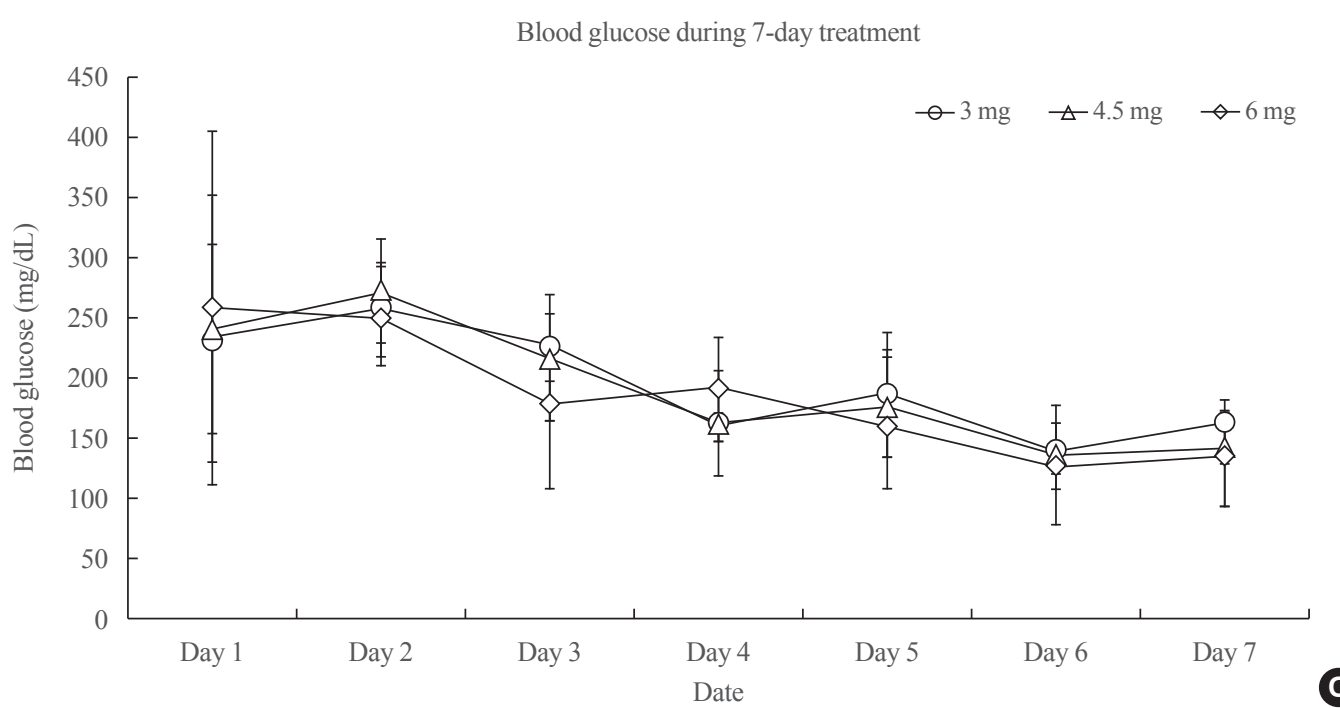

Fig. 2. Seven-day treatment of BIM23B065 at different concentrations. (A) Insulin-like growth factor-1 (IGF-1) level change in each group after BIM23B065 treatment. (B) Weight change before and after BIM23B065 treatment and (C) daily blood glucose levels during treatment.

chimeric drug (BIM-23A760) was first synthesized to circumvent the issue of unresponsiveness to existing drugs [10-14,19]. This new chimeric molecule, which is a combination of the two most commonly used drugs for the treatment of pituitary diseases, is a potential drug candidate.

SST analogs and DAs act via different mechanisms. SST analogs have tumor static effects, while CAB (DA) causes apoptosis. As chimeric molecules exhibit two mechanisms, they are generally considered to possess the merits of both incorporated drugs and presumably have a synergistic effect. Previously synthesized chimeric molecules (BIM-23A760) have exhibited inhibitory effects on pituitary hormones such as GH and prolactin
(PRL); however, some molecules showed ineffective outcomes [11]. The examined chimeric molecule (BIM-23A760) presented positive outcomes only in reducing tumor size in non-functioning pituitary adenoma in vivo [13]. Moreover, it has also been reported to show inhibitory effects on the secretion of GH and PRL in vitro only $[10,19]$. The present study showed that the chimeric molecule BIM23B065 is also effective in a pituitary adenoma mouse model.

According to the study that investigated the effects of an earlier version of this chimeric molecule, it was shown to suppress GH and PRL secretion from human acromegaly tumor cell cultures significantly better than individual SST analogs and DAs as 

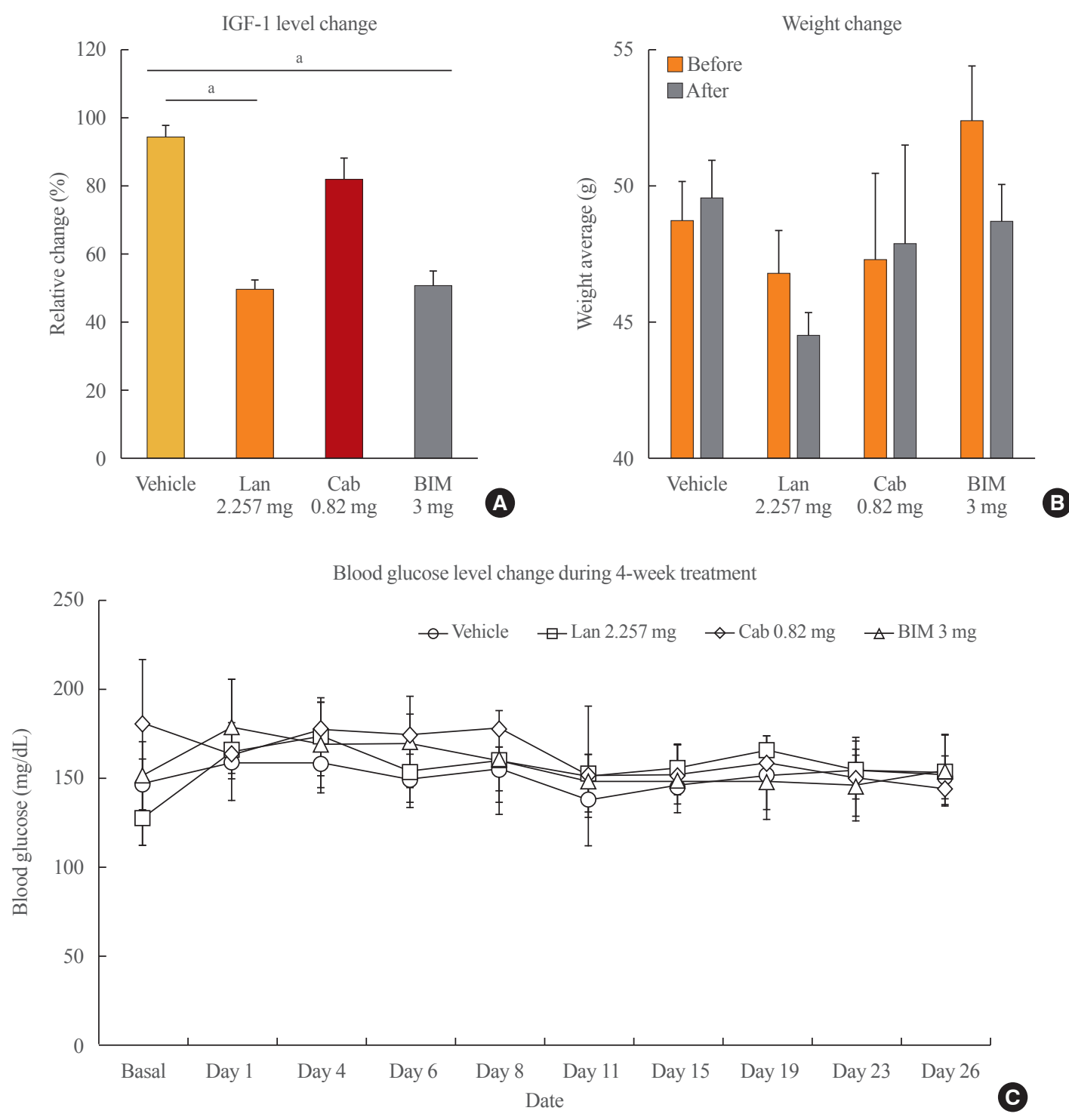

Fig. 3. Effects of lanreotide, cabergoline, and BIM23B065 after 4-week treatment in somatotroph-specific aryl hydrocarbon receptor interacting protein knockout (sAIPKO) mice. (A) Change in insulin-like growth factor-1 (IGF-1) level after 4-week treatment with lanreotide and BIM23B065. (B) Average weight change before and after treatment. (C) Change in blood glucose level throughout the treatment duration. ${ }^{\mathrm{a}} P<0.001$.

well as their combination. This indicated that it acts on receptors other than SST receptors [19]. However, after multiple dosing, an active metabolite of BIM-23A760 was formed and interfered with the parent compound, after which BIM-23A760 development was halted. Whereas, the main metabolite of BIM23B133 did not interfere with the parent compound, BIM23B065 and did not bind to any of the SST receptors, so BIM23B065 is more effective in reducing GH level and tumor size than BIM-23A760 [20].

The chimeric molecule (BIM23B065) in this study was comprised of a SST analog (lanreotide) and a DA (CAB) in a 1:1 ra- tio. The chimeric molecule and not individual drugs was used because of heterodimerization between SST/DA receptor, assuming that the chimeric molecule interacts more effectively than individual drugs $[11,19]$. Being a novel agent and not just a mixture of two drugs, BIM23B065 was observed to be significantly more effective in vitro than the mixture of lanreotide and CAB. In this study, we aimed to elucidate the mechanism of action of BIM23B065 in GH3 cells by investigating cell proliferation at different concentrations, CREB and ERK 1/2 phosphorylation, and changes in $\mathrm{GH}$ release.

BIM23B065 and lanreotide were similarly toxic to GH3 cells. 

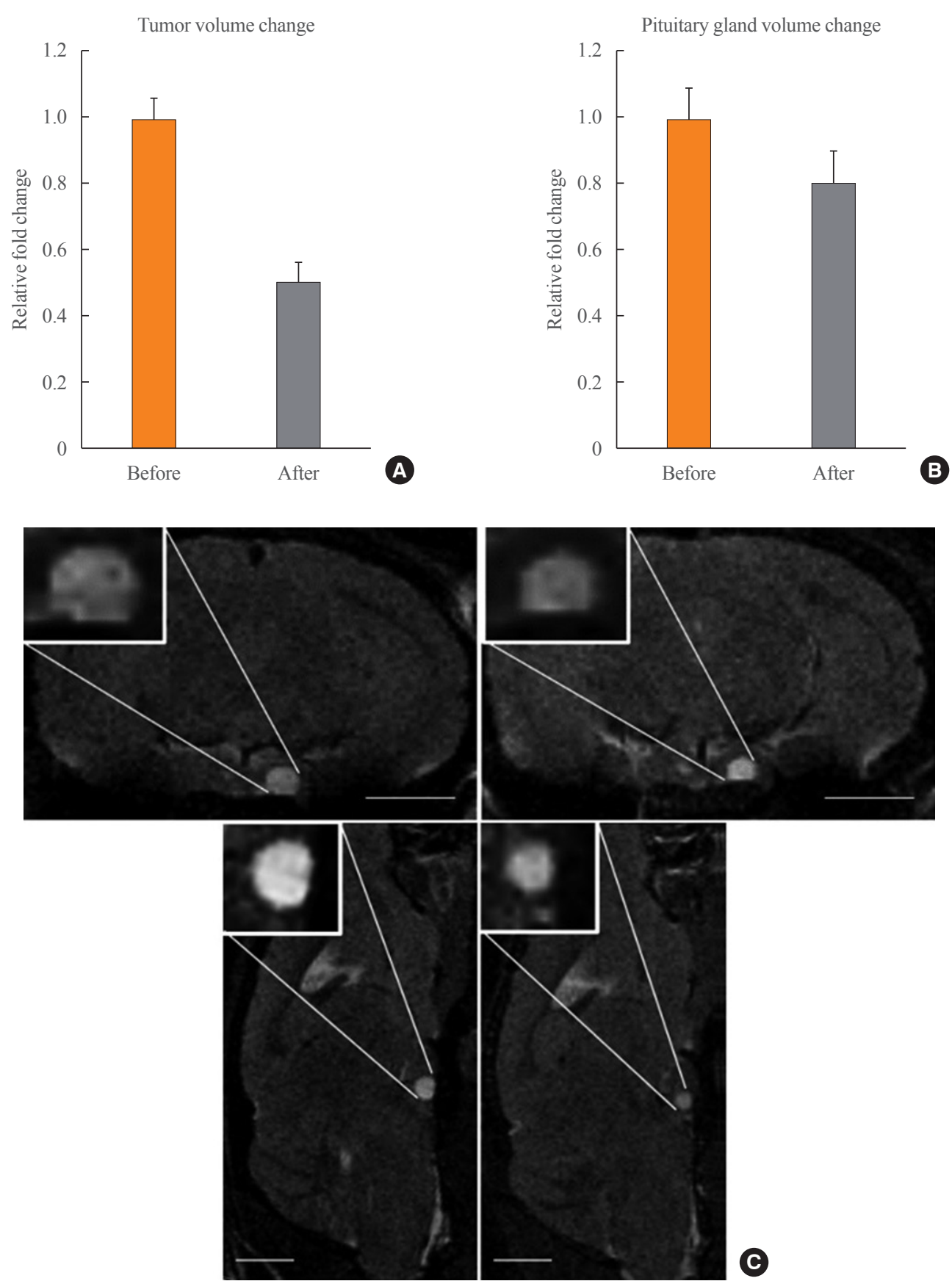

Fig. 4. Effects of BIM23B065 on tumor size and pituitary gland size in somatotroph-specific aryl hydrocarbon receptor interacting protein knockout (sAIPKO) mice. (A) Changes in average tumor volume after 4-week treatment. (B) Changes in average pituitary gland size after treatment and (C) magnetic resonance images before and after treatment showing decrease in tumor size in axial and sagittal views (white bar: $2 \mathrm{~mm})$.

However, $\mathrm{CAB}$ was effective at a much lower concentration than those of the other two drugs. Assuming that the chimeric molecule is made of a direct combination of a SST analog and a DA, the concentration of lanreotide administered to the animals was set equivalent to that of the chimeric molecule.
In vitro and in vivo tests confirmed that the chimeric molecule was effective in lowering pituitary hormone activity. The animal model used in the study was a novel acromegaly mouse model that exhibited the phenotype of pituitary hyperplasia and eventual growth of pituitary tumors as the mice aged [8]. The mice 
demonstrated similar clinical features to human acromegaly, wherein increased secretion of GH and expression of SST receptor type 2 (SSTR2), SSTR5, and dopamine receptor type 2 (DRD2) in the pituitary gland were observed.

After 7 days of treatment with BIM23B065 in sAIPKO acromegalic mice, the level of IGF-1 was not uniformly decreased in each dosage group. It was assumed that the IGF-1 level was influenced by mechanical stress induced in the mice during the pump implant surgery. Additionally, the duration of the pump (7 days) may have been too short for the drug to demonstrate its full effect. However, no change in body weight was observed, indicating that the drug was not toxic. Based on the results of this experiment, we performed a second 4-week study with the duration of the pump changed to 14 days, so that surgical intervention was required only once during the entire treatment. BIM23B065 was delivered via the 14-day pump at a dose of 3 $\mathrm{mg} / \mathrm{kg} /$ day.

The results of the second animal experiment were relatively uniform. Body weights and blood glucose levels were stable throughout the entire experimental duration. The IGF-1 level significantly decreased after BIM23B065 treatment as compared to after $\mathrm{CAB}$ and lanreotide treatment; the IGF-1 level in most of the BIM23B065-treated mice was reduced by $50 \%$ post-treatment.

Four weeks of treatment with BIM23B065 also significantly decreased tumor mass and size of the pituitary gland. Two of three sAIPKO mice with pituitary adenoma had hyperplastic tumors. Although MRI results may not be significant, it showed the size of tumor and hyperplasia pituitary shrinkage. Therefore, BIM23B065 could possibly be used in patients with pre-tumor abnormalities.

There are certain limitations to this study. First, the results showed that BIM23B065 had a similar effect to SST analogs, which was used as a positive control in the animal study. SST analog was ineffective in GH3 cells, but effective in animal model; however, the DA showed opposite effects. BIM23B065 was effective both in GH3 cells and in the animal model. Indeed, when applied to patients with sporadic GH-secreting pituitary adenoma caused by various genome changes, chimeric molecules may be effective in patients with non-responsive to lanreotide, but human studies have not confirmed in this study. Second, the sample size $(n=5)$ was small. All five animals had hyperplasia and three of them had tumors. The effects of the drug were observed in all the animals compared with the control group. Thus, the chimeric molecule is effective in both hyperplasia and pituitary tumors. Third, it was impossible to fully un- derstand the effects of BIM23B065 on metabolic parameters. The physical activity and blood glucose levels of the animals remained stable throughout the study, but there may be complications associated with the use of the novel drug. No adverse effects were observed in the liver and kidney; however, other side effects could exist. Therefore, examination of long-term effects with a larger number of experimental animals will be required in further studies. Finally, dose-dependent experiments of lanreotide and $\mathrm{CAB}$ could not be carried out in GH-secreting pituitary adenomas animal model. In the case of BIM series in both in vitro and in vivo, the treatment concentrations were determined after confirming the dose-dependent efficacy, and the same concentrations of lanreotide corresponding to the BIM series were treated. In the case of $\mathrm{CAB}$, we proceeded with reference to existing paper references. Since we focus on the effects of the BIM series, the does-dependent experiments of lanreotide and $\mathrm{CAB}$ could not be carried out. Also, even in MRI results, the purpose of the study was to analyze the effects of biochemical activity on the primary end point. The analysis of tumor size changes in the animal model for the use of lanreotide and $\mathrm{CAB}$ did not proceed due to the limitation of the number of MRIs in experimental animals at the medical institution.

Previous studies have confirmed the inhibitory effect on cell proliferation and hormone secretion only in vitro [10-14,19]. This study showed that BIM23B065 effectively decreased not only GH release in GH3 cells, but also IGF-1 levels in a GH-secreting pituitary adenoma mouse model. The reduction of hormone activity by BIM23B065 in vivo shows promising results for its future clinical use. However, GH levels remained unchanged (data not shown). This could be because $\mathrm{GH}$ is released in a pulsatile manner every three hours and could not be monitored at the accurate time. In addition, $\mathrm{GH}$ is a stress hormone that is sensitive to anesthesia or orbital venous congestion. The secretion of IGF-1, stimulated by GH, decreased. The chimeric molecule showed distinct effects compared to those of the combination of lanreotide and $\mathrm{CAB}$, indicating that this is a novel drug and not just a mixture of two drugs. Based on the results of this study, BIM23B065 holds potential to be developed into a novel therapeutic agent for acromegaly. Future studies are warranted to investigate its effects further.

\section{CONFLICTS OF INTEREST}

Heather Harlem and Michael D. Culler belonged to Endocrinology Research, Ipsen Bioscience, Inc., but not relevant to this study. 


\section{ACKNOWLEDGMENTS}

This work was supported by a grant from the Korea Health Technology R\&D Project through the Korea Health Industry Development Institute funded by the Ministry of Health and Welfare, Republic of Korea (Grant HI15C1584 to Eun Jig Lee), by the Basic Science Research Program through the National Research Foundation of Korea (NRF) funded by the Ministry of Education (NRF-2017R1D1A1B03033587 to Cheol Ryong $\mathrm{Ku}$ ), and by the Korean Endocrine Society of New Faculty Research Award 2017 (to Cheol Ryong Ku).

\section{AUTHOR CONTRIBUTIONS}

Conception or design: J.K., J.H.O., C.R.K., E.J.L. Acquisition, analysis, or interpretation of data: J.K., J.H.O., H.H., M.D.C., C.R.K., E.J.L. Drafting the work or revising: J.K., J.H.O., C.R.K., E.J.L. Final approval of the manuscript: J.K., J.H.O., C.R.K., E.J.L.

\section{ORCID}

Jean Kim https://orcid.org/0000-0003-0047-8074

Ju Hun Oh https://orcid.org/0000-0003-0795-6649

Eun Jig Lee https://orcid.org/0000-0003-3231-9887

Cheol Ryong Ku https://orcid.org/0000-0001-8693-9630

\section{REFERENCES}

1. Katznelson L, Laws ER Jr, Melmed S, Molitch ME, Murad MH, Utz A, et al. Acromegaly: an endocrine society clinical practice guideline. J Clin Endocrinol Metab 2014;99:393351.

2. Melmed S, Colao A, Barkan A, Molitch M, Grossman AB, Kleinberg D, et al. Guidelines for acromegaly management: an update. J Clin Endocrinol Metab 2009;94:1509-17.

3. Chalabi M, Duluc C, Caron P, Vezzosi D, Guillermet-Guibert J, Pyronnet S, et al. Somatostatin analogs: does pharmacology impact antitumor efficacy? Trends Endocrinol Metab 2014;25:115-27.

4. Srirajaskanthan R, Watkins J, Marelli L, Khan K, Caplin ME. Expression of somatostatin and dopamine 2 receptors in neuroendocrine tumours and the potential role for new biotherapies. Neuroendocrinology 2009;89:308-14.

5. Gatto F, Hofland LJ. The role of somatostatin and dopamine D2 receptors in endocrine tumors. Endocr Relat Cancer 2011;
18:R233-51.

6. Hofland LJ, Feelders RA, de Herder WW, Lamberts SW. Pituitary tumours: the sst/D2 receptors as molecular targets. Mol Cell Endocrinol 2010;326:89-98.

7. Peverelli E, Giardino E, Treppiedi D, Meregalli M, Belicchi M, Vaira V, et al. Dopamine receptor type 2 (DRD2) and somatostatin receptor type 2 (SSTR2) agonists are effective in inhibiting proliferation of progenitor/stem-like cells isolated from nonfunctioning pituitary tumors. Int J Cancer 2017;140: 1870-80.

8. Gillam MP, Ku CR, Lee YJ, Kim J, Kim SH, Lee SJ, et al. Somatotroph-specific Aip-deficient mice display pretumorigenic alterations in cell-cycle signaling. J Endocr Soc 2017;1: 78-95.

9. Herman-Bonert VS, Zib K, Scarlett JA, Melmed S. Growth hormone receptor antagonist therapy in acromegalic patients resistant to somatostatin analogs. J Clin Endocrinol Metab 2000;85:2958-61.

10. Gruszka A, Culler MD, Melmed S. Somatostatin analogs and chimeric omatostatin-dopamine molecules differentially regulate human growth hormone and prolactin gene expression and secretion in vitro. Mol Cell Endocrinol 2012;362:104-9.

11. Ibanez-Costa A, Lopez-Sanchez LM, Gahete MD, RiveroCortes E, Vazquez-Borrego MC, Galvez MA, et al. BIM23A760 influences key functional endpoints in pituitary adenomas and normal pituitaries: molecular mechanisms underlying the differential response in adenomas. Sci Rep 2017;7: 42002.

12. Peverelli E, Olgiati L, Locatelli M, Magni P, Fustini MF, Frank G, et al. The dopamine-somatostatin chimeric compound BIM-23A760 exerts antiproliferative and cytotoxic effects in human non-functioning pituitary tumors by activating ERK1/2 and p38 pathways. Cancer Lett 2010;288:170-6.

13. Florio T, Barbieri F, Spaziante R, Zona G, Hofland LJ, van Koetsveld PM, et al. Efficacy of a dopamine-somatostatin chimeric molecule, BIM-23A760, in the control of cell growth from primary cultures of human non-functioning pituitary adenomas: a multi-center study. Endocr Relat Cancer 2008; 15:583-96.

14. Jaquet P, Gunz G, Saveanu A, Barlier A, Dufour H, Taylor J, et al. BIM-23A760, a chimeric molecule directed towards somatostatin and dopamine receptors, vs universal somatostatin receptors ligands in GH-secreting pituitary adenomas partial responders to octreotide. J Endocrinol Invest 2005;28(11 Suppl International):21-7.

15. Luque RM, Amargo G, Ishii S, Lobe C, Franks R, Kiyoka- 
wa $\mathrm{H}$, et al. Reporter expression, induced by a growth hormone promoter-driven Cre recombinase (rGHp-Cre) transgene, questions the developmental relationship between somatotropes and lactotropes in the adult mouse pituitary gland. Endocrinology 2007;148:1946-53.

16. Su QQ, Xiang ZF, Qin J, Guo MF, Liu QS. Effects of cabergoline on the fertility of female mice during early and late pregnancy, and potential for its use in mouse control. Crop Prot 2014;56:69-73.

17. Koganemaru G, Abe H, Kuramashi A, Ebihara K, Matsuo H, Funahashi H, et al. Effects of cabergoline and rotigotine on tacrine-induced tremulous jaw movements in rats. Pharmacol Biochem Behav 2014;126:103-8.

18. Zhou L, Liang X, Zhang L, Yang L, Nagao N, Wu H, et al.
MiR-27a-3p functions as an oncogene in gastric cancer by targeting BTG2. Oncotarget 2016;7:51943-54.

19. Saveanu A, Lavaque E, Gunz G, Barlier A, Kim S, Taylor JE, et al. Demonstration of enhanced potency of a chimeric somatostatin-dopamine molecule, BIM-23A387, in suppressing growth hormone and prolactin secretion from human pituitary somatotroph adenoma cells. J Clin Endocrinol Metab 2002;87:5545-52.

20. De Boon WMI, van Esdonk MJ, Stuurman FE, Biermasz NR, Pons L, Paty I, et al. A novel somatostatin-dopamine chimera (BIM23B065) reduced GH secretion in a first-inhuman clinical trial. J Clin Endocrinol Metab 2019;104:88391. 